\title{
Avaliação de impactos ambientais na rodovia MG - 010: Estudo de caso no vetor norte de Belo Horizonte (MG).
}

\author{
Evaluation of environmental impacts in the MG - 010: Case study in northern vector of \\ Belo Horizonte (MG).
}

Tiago Silva Alves de Brito ${ }^{1}$, Fernanda Carla Wasner Vasconcellos², Fernando Luís Pereira Oliveira ${ }^{3}$

\author{
${ }^{1}$ Mestre em Meio Ambiente e Turismo pelo Centro Universitário UNA - Centro Universitário UNA, Belo Horizonte, MG, \\ Brasil \\ ${ }^{2}$ Centro Universitário UNA, Belo Horizonte, MG, Brasil \\ ${ }^{3}$ Universidade Federal de Ouro Preto, Ouro Preto, MG, Brasil
}

\begin{abstract}
Resumo
O presente trabalho tem por objetivo avaliar os impactos ambientais da Rodovia MG - 010 no trecho entre Hospital Risoleta Neves até o Viaduto Avenida Senhor do Bonfim (início da MG - 424), localizada no município de Belo Horizonte (MG), no período de 1989 e 2010. Para dar base aos estudos utilizaram-se os softawares Global Mapper e ArcGis para confecção dos mapas temáticos da área, e, ainda, registro fotográfico in loco dos principais impactos as margens da rodovia. Os resultados demonstraram que em um período de 20 anos a MG - 010 sofreu alterações em todos os compartimentos ambientais: físico (surgimento de ravinas e voçorocas), biótico (introdução de espécies exóticas e aumento das áreas de mata) e socioeconômico (aumento da circulação de veículos, atração de comércios e serviços e alargamento das autovias). Dentre os fatores que contribuíram para o desencadeamento deste processo está a expansão urbana-industrial direcionada ao Vetor Norte de Belo Horizonte.
\end{abstract}

Palavras-chave: Expansão urbana, ArcGis, análise ambiental.

\begin{abstract}
The present study aims to assess the environmental impacts in the highway MG - 010 on the stretch between Hospital Risoleta Neves and Avenue Viaduct Senhor do Bonfim (onset of MG -424), located in the municipality of Belo Horizonte (MG), from 1989 and 2010. To underpin the studies we used the softawares Global Mapper and ArcGIS for confection of the thematic maps of the area, and also photographic record in situ of the main impacts margins of the highway. The results showed that in a period of 21 years MG - 010 has altered in all environmental compartments: physical (appearance of ravines and voçorocas), biotic (introduction of exotic species and increase in forest areas) and socioeconomic status (increased circulation vehicles, attracting businesses and services and broadening of avenue). Among the factors that contributed to the triggering of this process is the expansion of urban-industrial North Vector directed to Belo Horizonte.
\end{abstract}

Keywords: Urban expansion, ArcGis, environmental analysis. 


\section{Introdução}

O homem moderno sempre buscou compreender o espaço em que habita e as relações de sociabilidade que estão presentes nele. Aliado a isso, interesses de ordem política, econômica, social, ambiental e cultural motivaram as escolhas para o gerenciamento adequado. É sob esta ótica que emerge as atividades que alteram (positivamente e negativamente) as condições do ambiente, como por exemplo, a construção de barragens, edifícios, casas, parques, estabelecimentos comerciais, rodovias entre outras (ROBAINA, 2008).

As autovias permitem reorganizar os fluxos de uma cidade e possibilitam novas formas de expansão. Interligam municípios, estados e nações, e propiciam o desenvolvimento econômico da região. Porém, as ações realizadas pela construção e reestruturação de rodovias ocasionaram impactos em todo o meio ambiente, tornando-se um empreendimento complexo, passível de questionamentos e avaliações. A escolha do método para a avaliação de impactos ambientais, a esfera do empreendimento, os profissionais da equipe multidisciplinar e a responsabilidade (do Governo ou de empresas privadas) auxiliam nas decisões finais da avaliação e por isso, elas são passíveis de questionamentos.

Os impactos exercidos sobre o meio ambiente precisam ser avaliados corretamente, evitando danos irreversíveis em diferentes escalas e tempos. Para entender as transformações ocorridas, necessita-se esclarecer o conceito de impacto ambiental que, de acordo

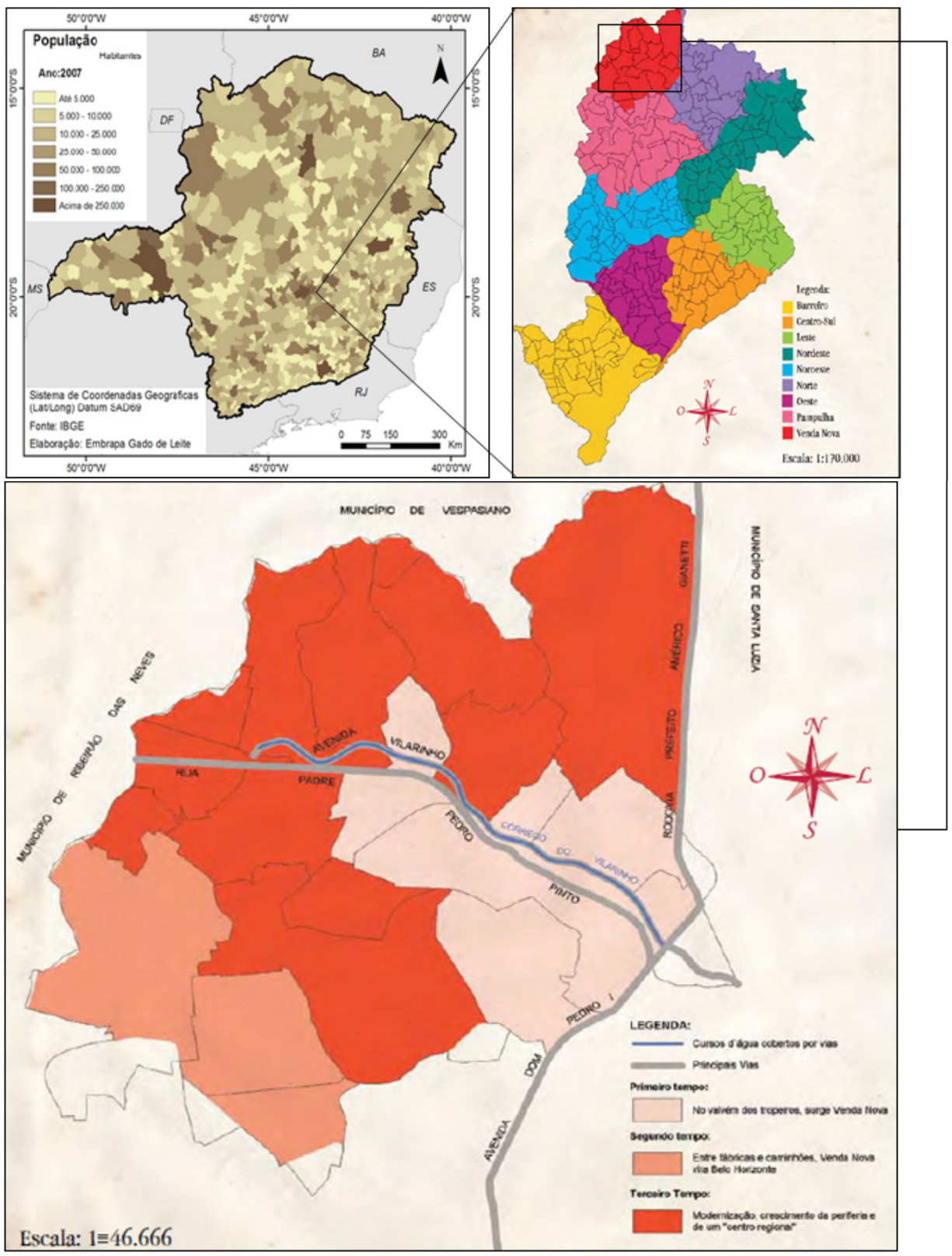

Figura 01 - Localização da Rodovia MG - 010 e o trecho da área de estudo.

Fonte: BRITO, 2012. 


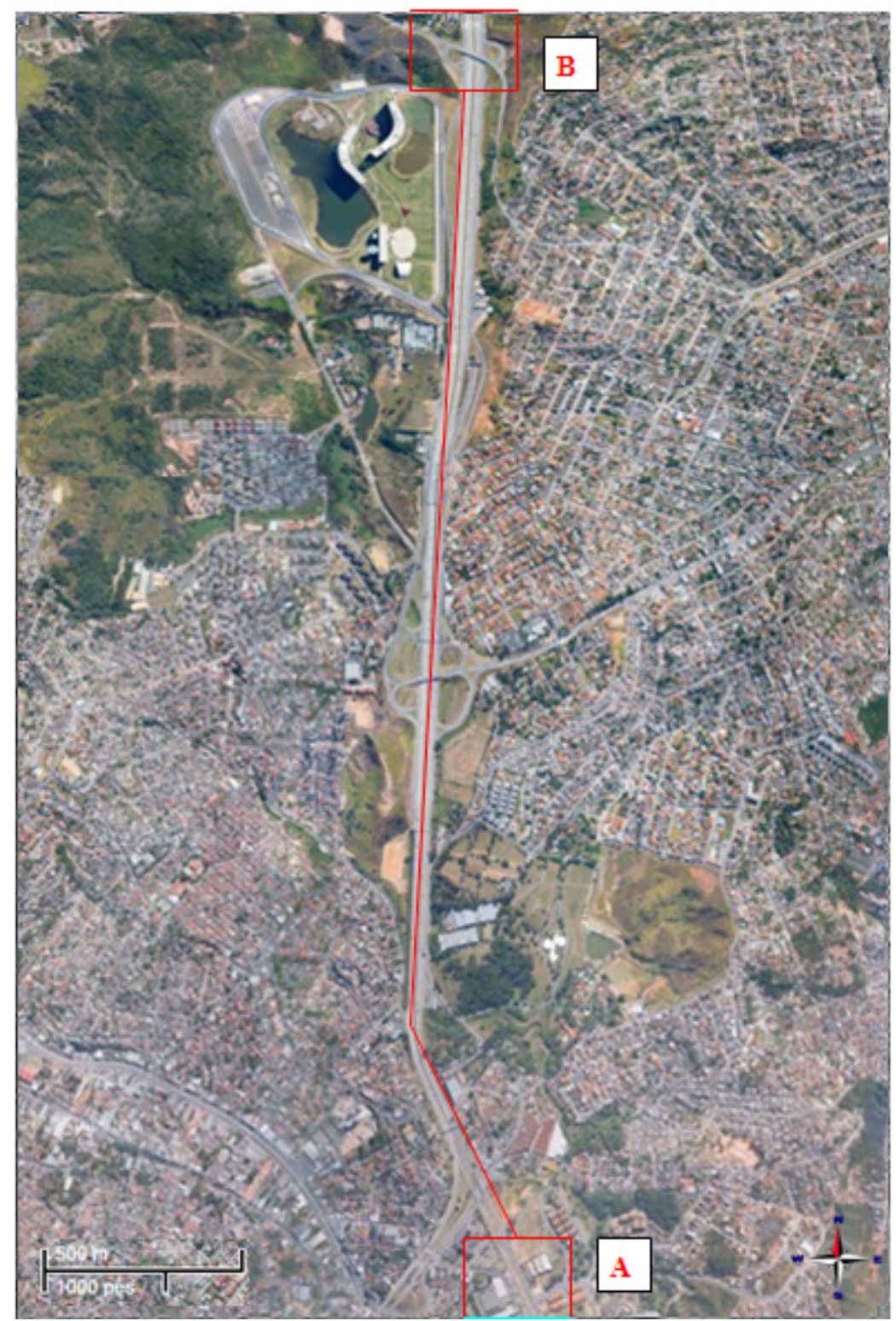

Figura 02 - Rodovia MG - 010 e o trecho estudado.

Fonte: BRITO, 2012.

com o art. 1ํ da Resolução CONAMA no 001/1986, é "qualquer alteração das propriedades físicas, químicas e biológicas do meio ambiente, causada por qualquer forma de matéria ou energia resultante das atividades humanas" e que afetam os diferentes compartimentos ambientais (BRASIL, 1986).

Segundo a Associação Nacional das Empresas de Obras Rodoviárias, as estradas de rodagem provocam extensas modificações territoriais, além das áreas de intervenção em seu eixo, compreendendo dimensões regionais, e, portanto, é um dos empreendimentos impactantes do ambiente (ANEOR, 1992).

No Brasil, o processo de urbanização permanece em constante ascensão, sendo as rodovias um dos símbolos do progresso dos municípios. Em Belo Horizonte (MG), foram observadas diversas inter- venções no que dizem respeito às obras de autopistas, tais como: expansão do eixo viário Linha Verde; as intervenções na Avenida Antônio Carlos e Avenida dos Andradas; remodelação do Complexo da Lagoinha; duplicação da Avenida Pedro I e reestruturação da Rodovia MG - 010, objeto deste estudo.

A Rodovia MG - 010 passa por importantes transformações de cunho socioeconômico e assume posição estratégica para interligar as multiplicidades apresentadas pela região (econômica, política, patrimonial-ambiental - região de Carste) e os municípios limítrofes, as quais se destacam: a Cidade Administrativa de Belo Horizonte, que concentra as Secretarias e os servidores do Estado; o Parque Estadual do Serra Verde, segundo maior parque do município (IEF, 2011); a Área de Proteção Ambiental do Carste Lagoa Santa, 
denominada o berço da paleontologia e espeleologia do Brasil (BERBET-BORN, 2002); o Parque Nacional da Serra do Cipó, caracterizado por altas taxas de endemismo e biodiversidade ainda incipiente nos estudos científicos (DAVIES et al., 1997); o Complexo da Pampulha, o Aeroporto Internacional Tancredo Neves, entre outros.

A demanda para construção e reestruturação de importantes autovias como a Rodovia MG - 010 na capital mineira, aliada à produção dos veículos automotores, promovem a desconfiguração do ambiente natural, podendo beneficiar, ou mesmo, prejudicar uma parcela dos habitantes. As obras já efetuadas geraram transtornos à população localizada nas regiões limítrofes dessa autovia, criando assim uma nova ordem de organização do espaço.

A partir do exposto, faz-se necessário uma avaliação sobre os impactos socioambientais provocados pela construção e reestruturação da Rodovia MG - 010 no trecho compreendido entre Hospital Risoleta Tolentino Neves (Ponto A) e Viaduto Senhor do Bonfim (Ponto B), onde inicia-se a Rodovia MG - 424 (Figura 01 e 02). Além disso, faz necessário,ainda, analisar as medidas de mitigação e compensação realizadas no trecho e construir elementos para subsidiar a avaliação de impactos ambientais em programa de gestão socioambiental no Vetor Norte de Belo Horizonte.

\section{Materiais e Métodos}

Os procedimentos analíticos utilizados para a avaliação dos impactos ambientais foram imagens aéreas do ano de 1989 fornecidas pela Empresa de Informática e Informação do Município de Belo Horizonte (PRODABEL), e imagem de satélite QuickBird e Geo Eye do ano 2010. A primeira na escala de 1:8000 e a segunda na escala de 1:2000, sendo as mesmas disponibilizadas em formato jpeg e sem informação espacial. A partir disso, as imagens de satélite foram georreferenciadas e, nelas, inseridas informações cartográficas (escala, Norte, referência, título, projeção, datum, data e formato) adotada como base uma imagem com informação espacial preexistente.

Após este processo, as cenas foram acopladas, a fim de gerar apenas uma imagem de cada ano para facilitar a análise dos impactos ambientais, como expansão da área urbana, supressão vegetal, criação de extensas áreas verdes localizadas, expansão da área industrial e diminuição das áreas de solo exposto. A escolha do período de 1989 e 2010, justifica-se pelo material encontrado no arquivo da PRODABEL referente à MG - 010 e pelas mudanças espaço-temporais ocorridas dentro do período de 21 anos em todos os compartimentos ambientais afetados.
Para realização do tratamento das imagens, como georreferenciamento, mosaico e equalização das cenas, utilizou-se o Software Global Mapper. Para a elaboração dos mapas de uso e ocupação do solo utilizou-se o software ArcGIS.

Para vislumbrar os principais impactos ambientais na área de estudo (demonstrados no tópico resultados e discussão), utilizou-se, ainda, o registro fotográfico por meio de câmera digital Sony DSC-W380, 14.1 mega pixels, $5 x$ zoom óptico e tela LCD de $2,7 \mathrm{~cm}$. O registro ocorreu nos dias 6 e 7 de Dezembro de 2011, em dia de semana (respectivamente terça-feira e quarta-feira), no horário entre 08:00 a.m. às 12:00 a.m.. Os impactos visualizados foram demarcados com uma seta vermelha, nas fotografias.

A abordagem teórica da pesquisa está ancorada nas perspectivas apresentadas por Minayo (2005) que relata a importância do método qualitativo para compreender e interpretar as ações sociais produzidas no espaço e em Câmara et al. (2009), o qual enfatiza a análise espacial como método que possibilita mensurar propriedades do ambiente por meio da localização espacial do fenômeno em sua área de estudo.

\section{Resultados e Discussão}

A partir dos softwares utilizados para a produção das imagens, foram gerados os mapas temáticos de 1989 e 2010. O objetivo foi avaliar os impactos socioambientais provocados pela construção e reestruturação da Rodovia MG - 010 no trecho compreendido entre Hospital Risoleta Tolentino Neves e Viaduto Senhor do Bonfim, e, ainda, analisar as medidas de mitigação e compensação realizadas no trecho e construir elementos para subsidiar avaliação de impactos ambientais em programa de gestão socioambiental no Vetor Norte de Belo Horizonte.

No ano de 1989, O Vetor Norte de Belo Horizonte (MG) e a Rodovia MG - 010 apresentavam o aspecto assinalado na Figura 03, com pequenas regiões voltadas para produção agrícola, o que já demonstrava a ruptura do modelo antigo de organização do espaço da região (onde predominava as áreas agrícolas); o surgimento discreto de áreas industriais ao entorno da Rodovia; a contínua expansão da área urbana potencializada pela ineficácia das medidas de proteção do uso e ocupação do solo; as áreas restritas de Mata, que teve sua área original exaurida pela ocupação urbana; e extensas áreas de pasto sujo, que são terras utilizadas para diversos fins.

Esta análise encontra-se em consonância com os estudos de Coutinho (1997), em que a fitofisionomia citada propicia a degradação e o restabelecimento de espécies vegetais devido ao constante uso para fins urbanos e agrícolas. 

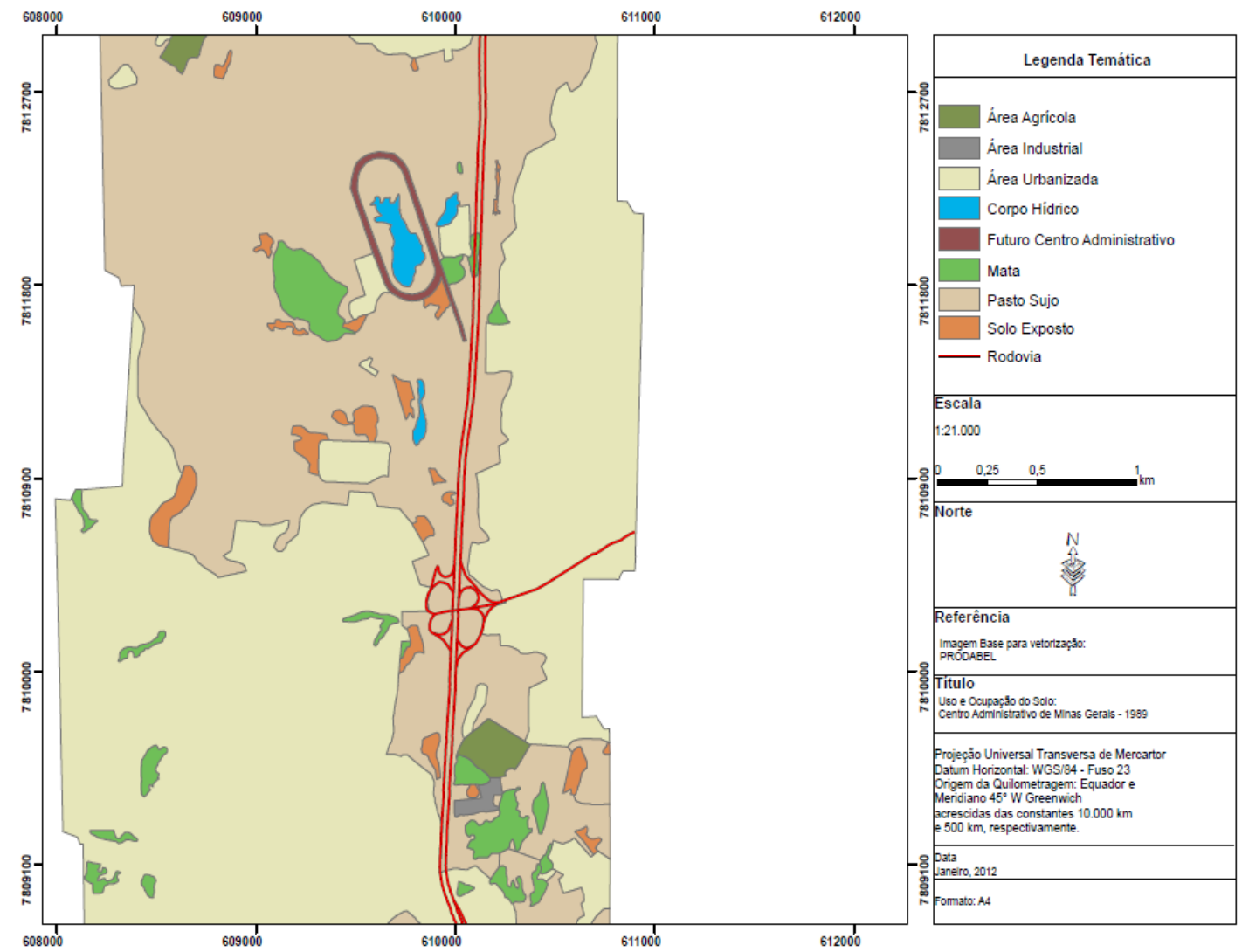

Figura 03 - Rodovia MG - 010 e o esboço do uso da terra em 1989.

Fonte: BRITO, 2012.

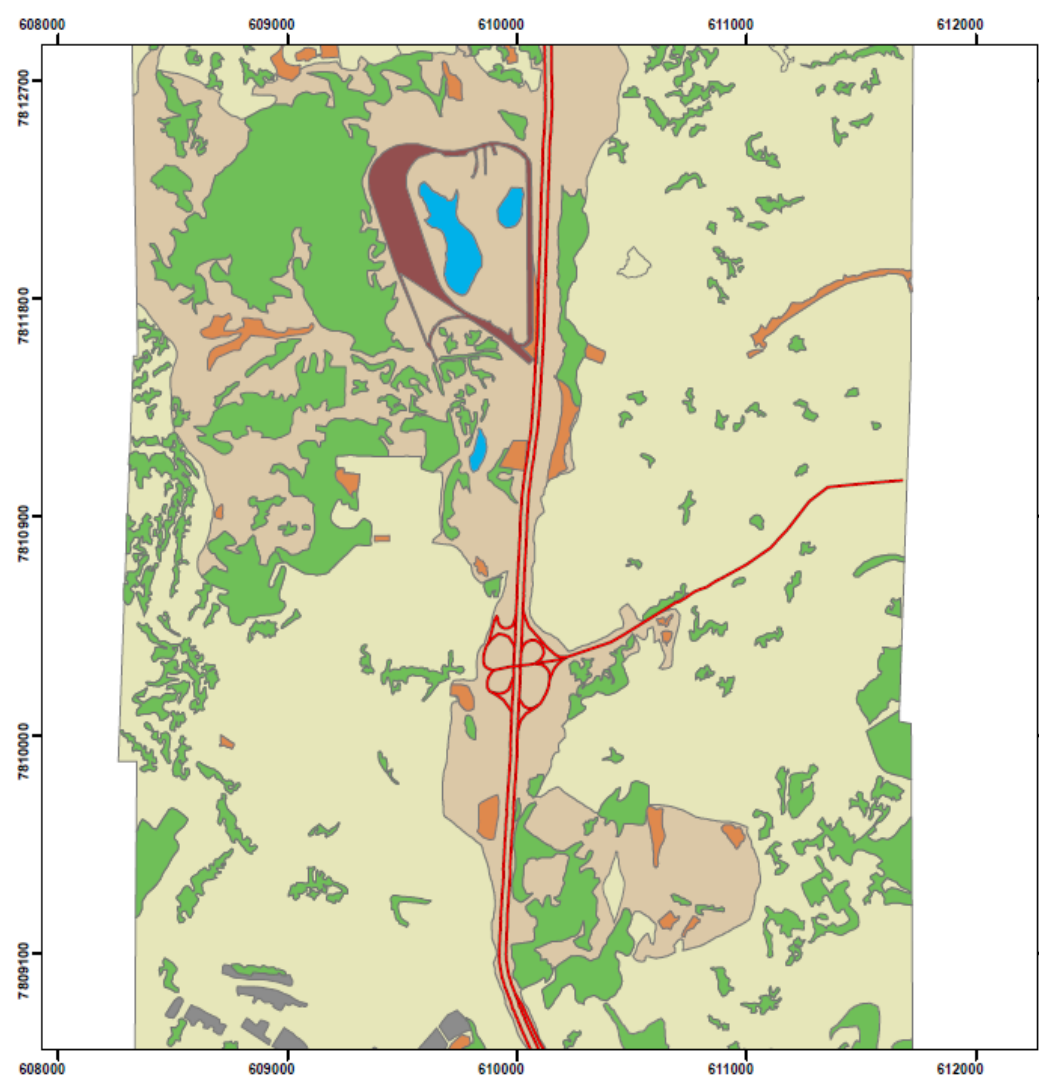

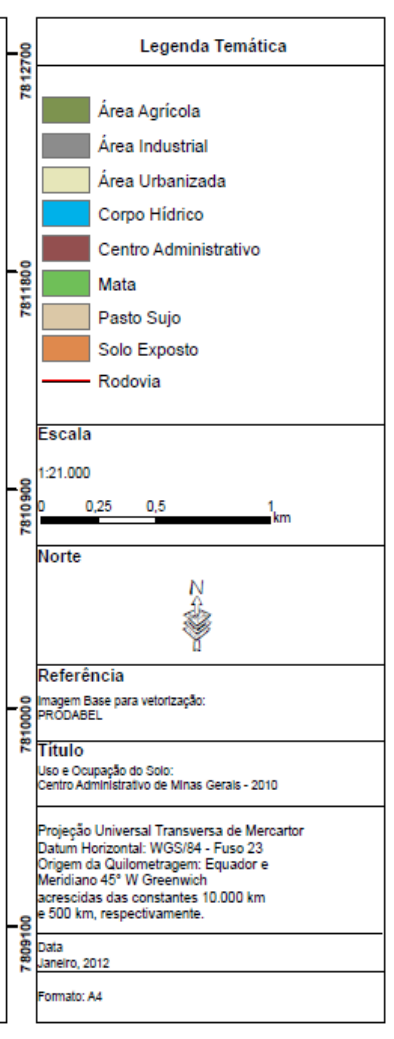

Figura 04 - Rodovia MG - 010 e o esboço do uso da terra em 2010.

Fonte: BRITO, 2012. 
A Figura 04 demonstra a configuração do uso e ocupação do solo na região no ano de 2010 e como se encontra o entorno da Rodovia MG - 010. A escolha do ano justifica-se por ser a última atualização das imagens pelos órgãos de planejamento urbano de Belo Horizonte (PRODABEL).

Dentre as observações que podem ser feitas, destacam-se: ampliação e conservação das áreas de mata, mesmo que não consolide a criação do Parque Estadual do Serra Verde com 142 hectares e faça parte do Sistema de Áreas Protegidas (SAP) do Vetor Norte da Região Metropolitana como proposto (IEF, 2011); concentração das áreas industriais em apenas uma região (porção Sudoeste da Rodovia as demais são direcionadas para o Vetor Norte da Região Metropolitana); área urbanizada com pouco índice de crescimento (a região não possui limites de crescimento dentro do município, sendo este direcionado para o Vetor Norte da Região Metropolitana de Belo Horizonte); diminuição considerável das áreas de solo exposto e pasto sujo, cedendo lugar as

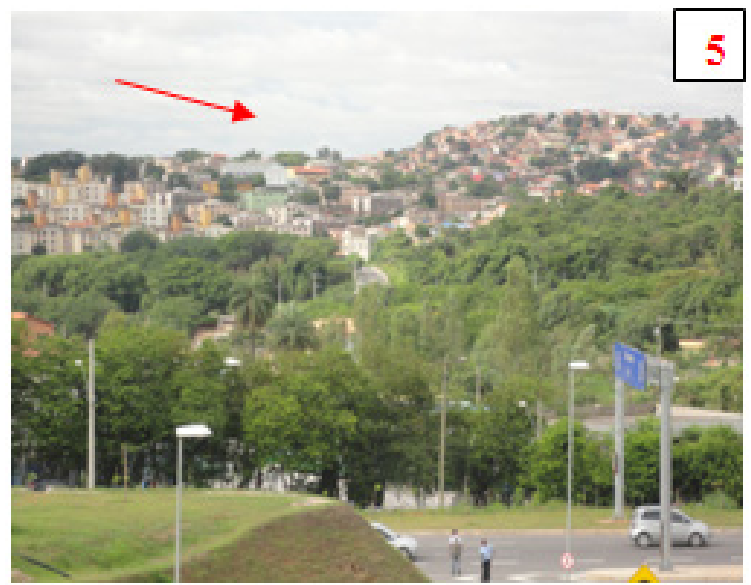

Figura 05 - Impacto referente à expansão urbana com supressão vegetal próximo as margens da MG - 010 .

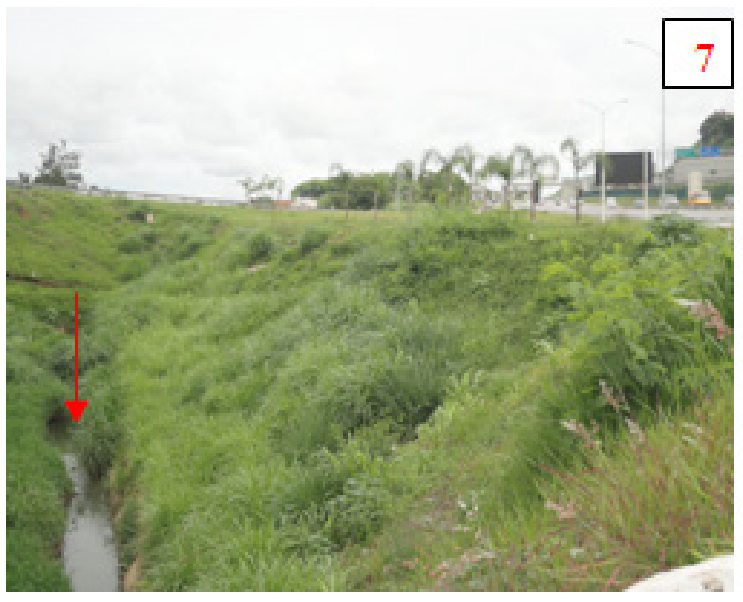

Figura 07 - Impacto esgoto a céu aberto as margens da MG -010 . áreas de mata e aos loteamentos dos terrenos para construção civil.

A construção da Cidade Administrativa de Minas Gerais, a reestruturação da Rodovia MG - 010 (Figura 06) e a expansão do setor imobiliário no decorrer dos anos modificaram amplamente a paisagem do Vetor Norte de Belo Horizonte, como cortes no relevo, introdução de espécies exóticas, reorganização do espaço urbano, aumento da circulação de veículos e obras de infraestrutura. Para Almeida e Sartori (2008), esta paisagem urbana cortada por edifícios, autovias, negócios e intensa movimentação de pessoas desencadeiam, nos ambientes urbanos, situações caóticas e estressantes, que nada mais são do que a representação visual/material do mundo moderno.

Dentre os impactos observados às margens da MG - 010, constataram-se alterações na altimetria em partes do relevo e na paisagem natural em relação à construída - casas, edifícios e conjuntos habitacionais (Figura 05); introdução de espécies exóticas da flora; supressão/acréscimo vegetal; uso

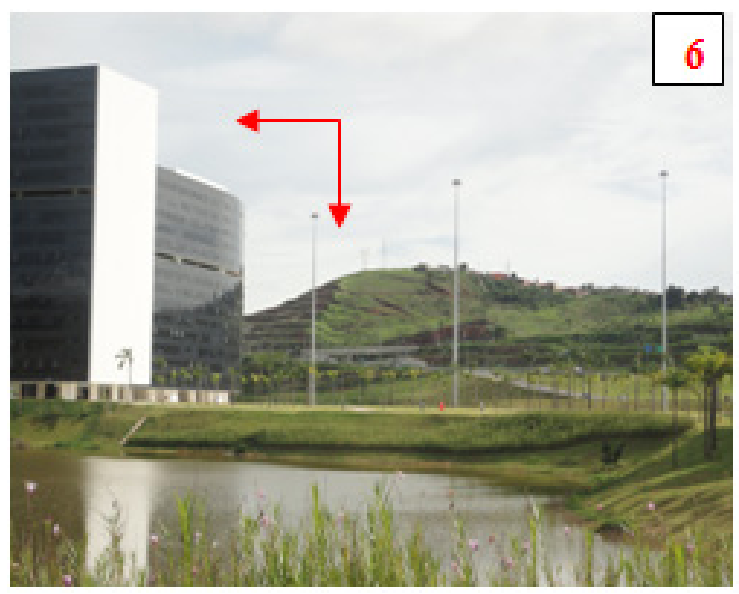

Figura 06 - Impacto visual e paisagístico com a construção da Cidade Administrativa de Minas Gerais às margens da MG - 010 .

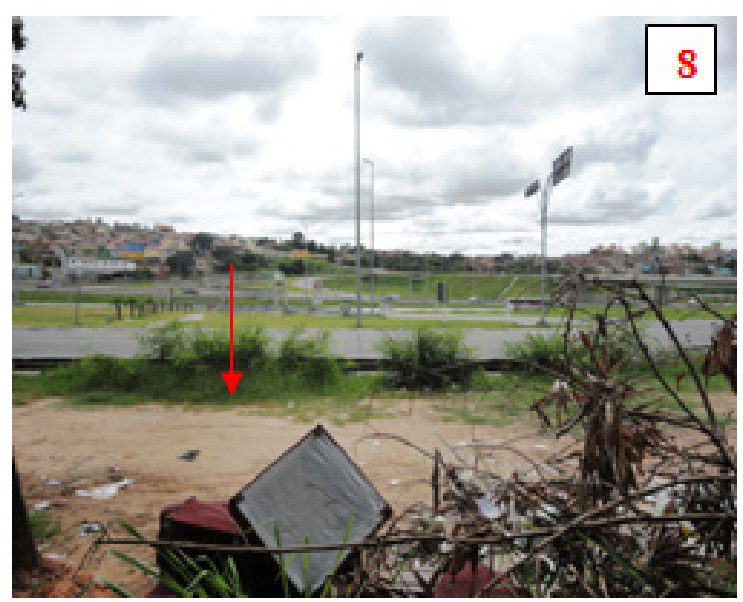

Figura 08 - Impacto resíduos sólidos descartados a céu aberto na MG-010. 
do solo para fins agrícolas e industriais; união/fragmentação de terrenos.

Situação semelhante é descrita no Manual de Diretrizes para Avaliação de Impactos Ambientais de Pernambuco, em que há degradação paisagística produzida pelo processo de terraplenagem no relevo para construção de rodovia, desmatamento das regiões lindeiras da autovia e disposição de resíduos da construção civil em terrenos baldios (PERNAMBUCO, 1998).

Os impactos apresentados nas Figuras 07 e 08 entram em consonância com as análises de Nasciutti (2009), em que o mau gerenciamento dos resíduos sólidos, principalmente os provenientes da construção civil, pode causar sérios impactos no meio ambiente, como a descaracterização da paisagem local, que proporciona ambientes favoráveis para a proliferação de vetores e a obstrução do escoamento pluvial, que ocasiona enchentes e entupimento de redes de saneamento.

Os impactos ambientais no meio físico podem ser visualizados principalmente por processos erosivos. Na Rodovia MG - 010, há ocorrência de voçorocas (Figura 09), desgaste dos solos (Figura 10), ravinas e processos que demonstram a erosão no entorno da autopista e a falta de manutenção. Nogami e Villibor (1995) afirmam que os processos de erosão são comumente encontrados na reconstrução de rodovias e devem ser objetos de estudos minuciosos, de modo a evitar efeitos danosos ao ambiente.

A causa da aceleração dos processos erosivos constitui um fator difícil de mensurar, pois boa parte deles depende da ação de fatores externos. No caso da Rodovia em estudo, nota-se que a eliminação de parte da cobertura vegetal associada à intempérie decorrente do escoamento pluvial, somado a ausência de medidas de mitigação, como construção de "canaletas" de escoamento ou terraplanagem compensada, proporcionou rupturas visíveis no solo.

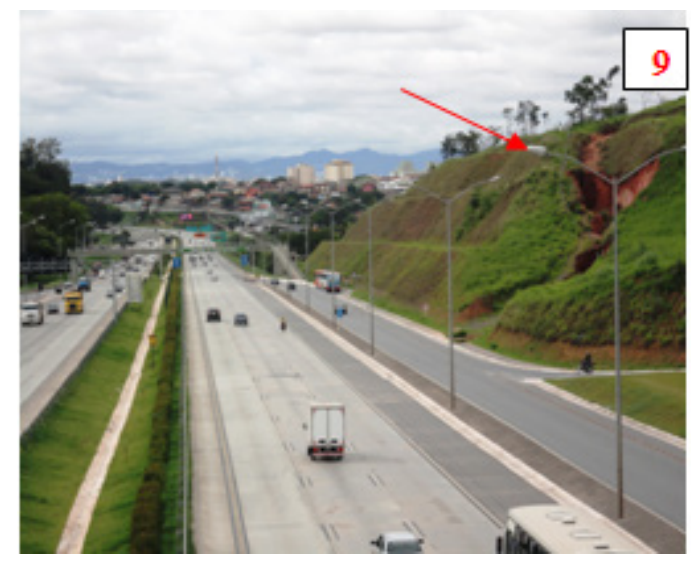

Figura 09 - Impacto Erosão na MG-010 próximo ao trevo do município de Santa Luzia (MG).
Situação semelhante é descrita por Guerra, Coelho e Marçal (1998) que expõem os problemas de desgaste do relevo associado a precariedade de investimentos na infraestrutura das Rodovias BR - 010 e BR - 222.

Outro fator importante no processo de desgaste do relevo está a construção involuntária de trilhas para travessia desta Rodovia (Figura 10). A localização das passarelas para travessia bem como as suas ausências, fazem com que a população atravesse a pista pulando o canteiro que separa as vias. $O$ pisoteio da vegetação aliado ao escoamento superficial da água, desgastam o solo e formam buracos e trilhas ao longo da Rodovia MG - 010 .

A travessia inesperada pelo canteiro, muitas vezes, é associada à perda de tempo que a população pode vir a ter ao atravessar pela passarela. Lisboa (2002) e Ferreira e Silva Júnior (2008) mencionam este fato ressaltando que os cidadãos muitas vezes precisam atravessar a Rodovia para cumprir suas funções sociais cotidianas. Entretanto, fatores como esses potencializam acidentes de trânsito e o desgaste do relevo/solo, sendo necessário a revitalização e o recapeamento sazonal das autovias.

Situação de acidentes em rodovias é vislumbrada por Ferreira (2009), que realizou estudos na própria rodovia MG-010 e relatou aumento de acidentes com vítimas nesta região, com registro no período de 2004 a 2007, de 712 acidentes, 1.845 vítimas, 56 vítimas de atropelamento e 22 vítimas fatais.

As modificações analisadas no percurso da Rodovia MG - 010 (Figuras 05 a 10) representam a área urbanizada no mapa da Figura 03, que demonstra os impactos ambientais no trecho de $6 \mathrm{~km}$ entre Hospital Risoleta Tolentino Neves e Viaduto Senhor do Bonfim. Cabe ressaltar que a instalação da Cidade Administrativa de Minas Gerais permitiu a expansão urbana direcionada ao Vetor Norte da capital, ampliando-se as alterações no trecho ao longo dos anos.

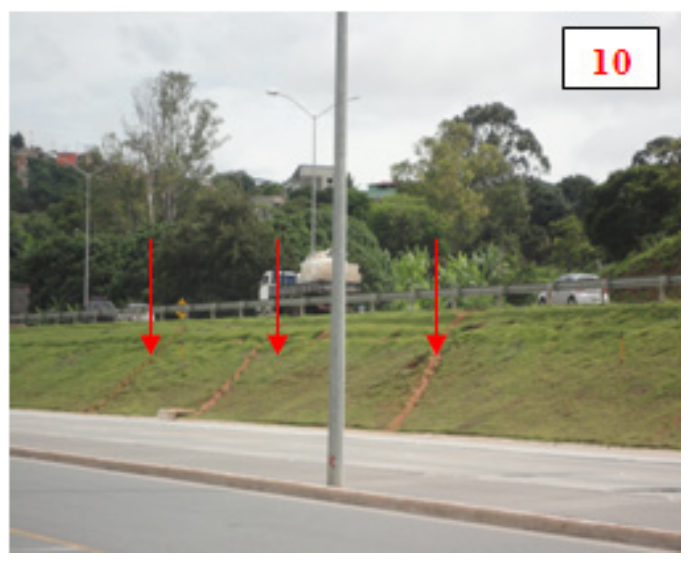

Figura 10 - Trilhas e infiltrações na MG-010 próximo a Cidade Administrativa de Minas Gerais. 
Portanto, nota-se que as constantes alterações ocorridas na Rodovia MG - 010 têm impactado todos os compartimentos ambientais (físico, biótico e socioeconômico), sendo a falta de monitoramento ambiental e o desrespeito à legislação urbana, fatores determinantes para a ampliação dos processos erosivos, mau gerenciamento dos resíduos líquidos e sólidos, e a descaracterização da paisagem local através da expansão urbana em demasia.

As medidas de mitigação da Rodovia - MG 010 (monitoramento dos processos erosivos) e compensação da Cidade Administrativa de Minas Gerais (adoção do Parque Estadual do Serra Verde) não foram fiscalizadas/cumpridas, o que, de fato, aumenta os impactos ambientais negativos na região (FEAM, 2009).

Para buscar melhorias na gestão da Rodovia sugere-se a efetivação de programas de Gestão Socioambiental que contemplem os diversos aspectos do meio ambiente para mitigação e compensação dos impactos relatados na área de estudo, sendo estes pautados em uma visão interdisciplinar e fundamentada no conceito de sustentabilidade, utilizando-se dos fundamentos da AIA e da percepção do ambiente por meio dos sujeitos que o habitam/vivenciam as alterações socioespaciais.

\section{Conclusões}

Diante dos estudos realizados, nota-se que a Rodovia MG - 010 constitui um corredor viário importante no município de Belo Horizonte (MG) e Região Metropolitana por alocar a Cidade Administrativa do estado, e ainda interligar importantes regiões de Minas Gerais.

Entretanto, as obras de reestruturação da Rodovia MG - 010 atrelada a expansão urbana e ao novo fluxo de veículos no local, potencializaram ainda mais os impactos, ocasionando problemas aos usuários e moradores no entorno. Intensificação dos processos erosivos, aumento do tempo de travessia, ausência no gerenciamento dos resíduos líquidos e sólidos e a desconfiguração da paisagem local constituem alguns dos impactos visualizados ao longo do trecho estudado na Rodovia MG - 010.

Assim, para execução de obras no Vetor Norte de Belo Horizonte e demais regiões que se utilizam de rodovias como aporte para o desenvolvimento, sugere-se a adoção de um programa de gestão socioambiental que elabore: (i) diagnóstico ambiental da área de estudo; (ii) levantamento documental de EIA/ RIMA e RCA/PCA de empreendimentos impactantes da área; (iii) consulta a legislação em todas as suas esferas (federal, estadual e municipal), ressaltando os Planos Diretores das cidades afetadas bem como a Lei de Uso e Ocupação do Solo; (iv) utilização de softwares para análise espacial da área de estudo; (v) escolha de métodos de avaliação de impactos ambientais para dimensionar as alterações no ambiente; e (vi) elaboração de relatório técnico emitido pela equipe multidisciplinar, relatando as potencialidades e fragilidades do local afetado.

\section{Referências}

ALMEIDA, A. P.; SARTORI, M. G. B.. A percepção da paisagem urbana de Santa Maria-RS e os sentimentos de topofilia e topofobia de seus moradores. Ciência e Natura, UFSM, 30 (2) : $107-$ 126, 2008. Disponível em: <http://cascavel.ufsm.br/ revista_ccne/ojs/index.php/cienciaenatura/article/ view/247/215>. Acesso em: 03 set. 2012.

ANEOR. Associação Nacional das Empresas de Obras Rodoviárias. Guia de diretrizes para Obras Rodoviárias. Brasília: 1992. 95 p.

BERBET-BORN, M. Carste de Lagoa Santa MG. Berço da paleontologia e da espeleologia brasileira. In: SCHOBBENHAUS,C. et al. (Edit.). Sítios Geológicos e Paleontológicos do Brasil. Brasília: 2002. p. 415-430. Disponível em: <http://sigep. cprm.gov.br/sitios.htm\#Vol1>. Acesso em: 10 set. 2010 .

Resolução CONAMA nº 001 de 23 de janeiro de 1986. Dispõe sobre os critérios básicos e as diretrizes gerais para uso e implementação da Avaliação de Impacto Ambiental. Brasília, 1986. Disponível em: <http://www.mma.gov.br>. Acesso em: 07 set. 2010.

BRITO, T. S. A. Avaliação de impactos ambientais no Vetor Norte de Belo Horizonte - MG: estudo de caso da Rodovia Prefeito Américo Renê Gianetti (MG - 010). 2012. 171f. Dissertação (Mestrado em Turismo e Meio Ambiente) - Programa de Mestrado em Turismo e Meio Ambiente, Centro Universitário UNA, Belo Horizonte, 2012.

CÂMARA, G.; MONTEIRO, M. A. V.; MEDEIROS, S. J. Introdução à ciência da geoinformação. São José dos Campos: INPE, 2001. 344p.

COUTINHO, A. C. Segmentação e classificação de Imagens Landsat-Tm para o mapeamento dos usos da terra na região de Campinas, SP. 1997. 
147 f. Dissertação (Mestrado em Ecologia Geral) Departamento de Ecologia Geral do Instituto de Biociências da Universidade de São Paulo, USP, São Paulo, 1997. Disponível em: <http://www. segmenta.cnpm.embrapa.br/index.html>. Acesso em: 07 fev. 2012.

DAVIES, S.D.; HEYWOOD, V.H.; HERRERAMACBRIDE, O.; VILLA-LOBOS, J. \& HAMILTON, A. C. Centres of Plant Diversity: A Guide and Strategy for their Conservation. The Americas. Cambridge: IUCN Publications Unit, 1997. v.3. 578 p.

. Paracer Técnico COPAM no 01049/2007/003/2009. EIA/RIMA e RCA/PCA da Cidade Administrativa de Minas Gerais, 2009. Disponível em: $<$ http://www.feam.br $>$. Acesso em: 25 nov. 2011.

FERREIRA, M. A.G.; SILVA JÚNIOR, S.B. Rodovias em áreas urbanizadas e seus impactos na percepção dos pedestres. Revista Sociedade \& Natureza, Uberlândia, v. 20, n. 1, p. 221-237, jun. 2008. Disponível em: < http://www.scielo.br/pdf/ sn/v20n1/a15v20n1.pdf>. Acesso em: 25 dez. 2010.

FERREIRA, S.B. Análise de acidentes de trânsito ocorridos na Rodovia MG - 010 antes e depois da implantação do projeto viário Linha Verde. 2009. 47 f. Monografia (Pós-Graduação em Administração Pública) - Fundação Getúlio Vargas, Belo Horizonte, 2009. Disponível em: < http://www.der.mg.gov.br/saiba-sobre/trabalhostecnicos/1067-trabalhos-academicos- >. Acesso em: 12 set. 2010.

GOOGLE MAPS, 2012. Imagem da Rodovia MG - 010. Disponível em: <http://maps.google.com.br/ maps?hl=pt-BR\&tab=wl>. Acesso em: 28. Set. 2012.

GUERRA, A. J.T.; COELHO, M. C. N.; MARÇAL, M. dos S. Açailândia, Cidade Ameaçada pela Erosão. Ciência Hoje, Rio de Janeiro, v. 23, n. 138, p. 36-45, 1998.

IEF. Instituto Estadual Florestal. Parque Estadual Serra Verde. 2011. Disponível em: <http://www. ief.mg.gov.br/areas-protegidas/572?task=view $>$. Acesso em: 14 dez. 2011.

LISBOA, M. V. Contribuição para a tomada de decisão na classificação e seleção de traçados para rodovias em trechos urbanizados. 2002. 194f. Dissertação (Mestrado em Engenharia de
Transportes) - Escola Politécnica da Universidade de São Paulo, Universidade de São Paulo, São Paulo, 2002. Disponível em:<http://www.teses.usp. br/teses/disponiveis/3/3138/tde-24042003-183416/ pt-br.php >. Acesso em: 02 set. 2010.

MINAYO, M. C. de S.; (Org.). Avaliação por triangulação de métodos: abordagem de programas sociais. Rio de Janeiro: Fiocruz, 2005.

NASCIUTTI, A. B. C. T. Melhores práticas de gestão de resíduos da construção civil: $\mathrm{O}$ caso do Município de Campinas - SP. 2009. Dissertação (Mestrado em Turismo e Meio Ambiente) - Centro Universitário UNA. Belo Horizonte, 2009. 112p.

NOGAMI, J. S.; VILLIBOR, D.F. Pavimentação de baixo custo com solos lateríticos. São Paulo: Villibor, 1995.

PERNAMBUCO. Manual de Diretrizes para Avaliação de Impactos Ambientais - (MDAIA). Companhia Pernambucana do Meio Ambiente. Recife: CPRH/GTz , 1998. 125 p.

ROBAINA, L. E. S. Espaço urbano: relação com os acidentes e desastres naturais no Brasil. Ciência e Natura, UFSM, 30 (2) : 93-105, 2008. Disponível em: <http://cascavel.ufsm.br/revista_ccne/ojs/ index.php/cienciaenatura/article/view/246/214>. Acesso em: 03 set. 2012. 